\section{Machine language programs for high-speed transfer of data between the KIM-1 and the CBM/PET microcomputers}

\section{JAMES CAMPBELL}

University of Wollongong, Wollongong, New South Wales, Australia

In the system described here, the CBM/PET microcomputer is used for processing data, and the more portable and less expensive 6502 KIM- 1 is used for data logging. Combining these features involves the transfer of data from the KIM to the PET. This is essentially the practice I follow in laboratory studies of insect behavior. The locomotory activity of field crickets is monitored under a variety of conditions (see Campbell \& Loher, 1983). The data are logged using KIM units and are periodically transferred to a PET for processing. The main aim of this paper is to explain the datatransfer system. The data-logging equipment will be described in a later paper.

The system should be easily modifiable for operation with other 6502-based units, for example, SYM to Apple. The possible interfaces with the programs provided are: KIM to PET, PET to KIM, PET to PET, and KIM to KIM.

Rhenke (1981) described a similar high-speed datatransfer system, but it cannot be used for moving data from a KIM to a PET, because the B port of the PET is not available to the user and the eight $A$ port lines are used for the data transfer. Fortunately, it is possible to program the CB2 line of the PET 6522 VIA as a single bidirectional handshake line with any available KIM B port line. Details for programming the 6522 are given by Zaks (1979). Another advantage of the system described in this paper is that a checksum routine is provided to ensure that the transfer of data has occurred without error.

Hardware. The two units are connected via the eight A port lines of the KIM and those of the user port of the PET, plus two other connections, PB5 of the $\mathrm{KIM}$ to $\mathrm{CB} 2$ of the PET and a common ground line. PB5 of the KIM was used because PB0, PB1, PB2, and PB3 were dedicated for other purposes. Figure 1 shows the wiring details.

Programs. Instructions on machine language programming for both the KIM and PET are given in the manuals that come with these microcomputers and should be referred to if necessary.

Four machine language programs are provided in this paper: KIM-OUT, PET-IN, PET-OUT, and KIM-IN. Listings are given in Table 1. The programs for the KIM

The author's mailing address is: Department of Biology, University of Wollongong, P.O. Box 1144, Wollongong, New South Wales 2500, Australia.

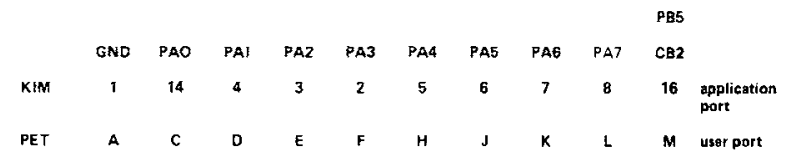

Figure 1. Cable connections for transfer of data between KIM and PET.

are located in the RAM space of the $6530 \mathrm{PI} /$ memory devices starting at address 1780 . Those for the PET are located in the second cassette buffer starting at address $033 \mathrm{~A}$. The programs are relocatable and can be placed anywhere in memory without modification, but the operating procedures described below are for the programs loaded at the addresses given above.

Operation. The operation of the data-transfer programs can be explained by reference to the flow diagrams given in Figure 2. For transfer of data from the KIM to the PET, the KIM-OUT and PET-IN programs are loaded. The start and end address pointers of the data block to be transferred are placed in zero page locations 0030 to 0033 (low order first) in both machines. The blocks specified should be of equal size. If the OUT block is smaller than the IN block, exit from the IN program will not occur. The KIM GO key is pressed at address 1780 . This initializes the OUT program of the KIM, which then stops at address 17A1 (A in Figure 2) after a break. The PET-IN routine is then started at address 033A. The PET remains in its WAIT loop (AA in Figure 2) until the KIM GO key is again pressed at address $17 \mathrm{~A} 1$. The specified block of data is then transferred from the KIM to the PET. If the transfer has been executed without error, the KIM and PET checksums will be equal. The checksums are located at address 0037 in both machines.

Table 1

Machine Code Listings for the KIM-PET Interface

\section{KLM-OUT}

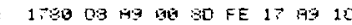
17.

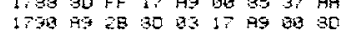

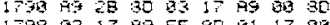

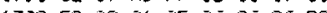
17AO EA Ag OS S5 35 Co 36 do

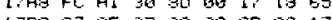

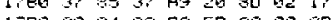

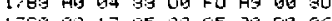

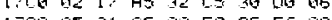

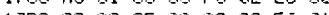
l.

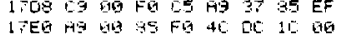

$$
\text { PET-IN }
$$

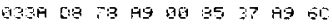
642
$\mathrm{BD}$

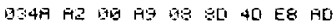

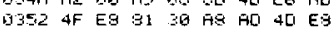

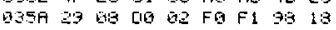

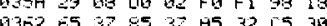

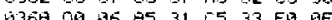
प36

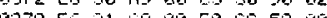

PET-OUT

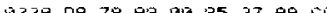

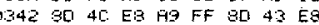
348 R?

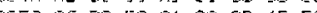

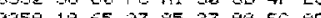

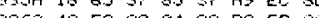
Gor 40 Eg ha ga so la fo ha

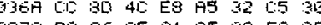

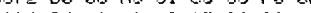
Gorf es sa ha ba cs ab 90 ba

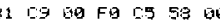
K LM-IN

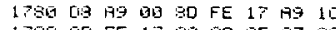

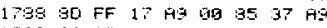

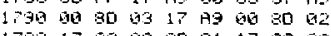

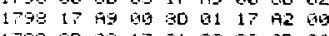

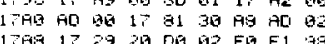

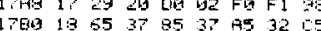
TEO 25 ST IT 7 . COC पD 00 10 00 मO 


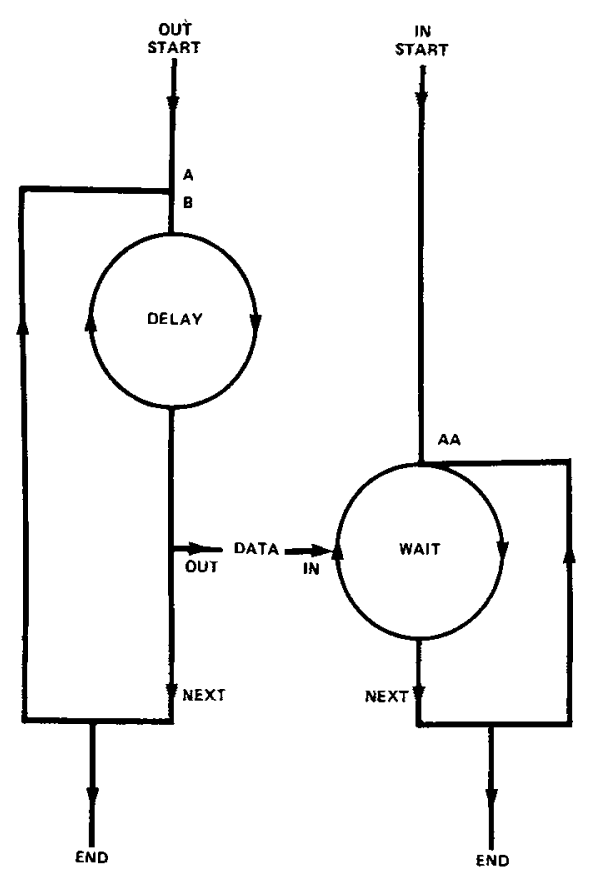

Figure 2. Flow diagrams of programs OUT and IN.

For synchronization to be achieved, IN must be in its WAIT loop before data can be transferred from OUT, and the internal interrupts of the PET must be disabled [SEI (78) at address 033B]. If synchronizing diffi- culties are encountered (if checksums are not equal), this could be resolved by placing a number $>01$, which gives the most rapid transfer of data, at address $17 \mathrm{~A} 2$ (B in Figure 2). This increases the delay loop of OUT. I have found that 01 works for KIM to PET and vice versa.

For transfer of data from the PET to the KIM, the PET-OUT and KIM-IN programs are loaded. The start and end addresses of the data block to be transferred are specified for both machines starting at address 0030 , as before. PET-OUT is run at address $033 \mathrm{~A}$ to initialize the program, which then stops at address 034D. KIM-IN is then started at address 1780 . KIM-IN remains in its WAIT loop until PET-OUT is restarted at address 034D. This is given by PC of the register pointers displayed on the screen after the initialization. The specified block of data is then transferred from PET to KIM.

Availability. Disassembled program listings with comments are available on request.

\section{REFERENCES}

CAMpeele, D. J., \& Loher, W. A microcomputer-based modulator for simulating insect songs and the response of crickets to an artificial calling song. Behavior Research Methods \& Instrumentation, 1983, 15, 538-541.

Rhenke, E. High-speed data transfer. Compute', January 1981, 126-130.

ZAKs, R. 6502 applications book. Berkeley, Calif: Sybex, 1979.

(Manuscript received for publication August 11, 1983.) 